\title{
Pharmacokinetics of intravenous busulfan as condition for hematopoietic stem cell transplantation: comparison between combinations with cyclophosphamide and fludarabine
}

\author{
Taku Kikuchi ${ }^{1}$ (1) $\cdot$ Takehiko Mori $^{1} \cdot$ Chikako Ohwada $^{2,3} \cdot$ Masahiro Onoda $^{4} \cdot$ Hiroaki Shimizu $^{5} \cdot$ Hiroki Yokoyama $^{6}$. \\ Makoto Onizuka ${ }^{7}$. Yuya Koda ${ }^{1}$. Jun Kato ${ }^{1}$ - Yusuke Takeda ${ }^{2}$. Yutaro Hino ${ }^{2}$. Tatsuzo Mishina ${ }^{2}$. Emiko Sakaida ${ }^{2}$. \\ Katsuhiro Shono ${ }^{4} \cdot$ Yuhei Nagao $^{4} \cdot$ Akira Yokota $^{4} \cdot$ Kana Matsumoto $^{8} \cdot$ Kunihiko Morita $^{8} \cdot$ Shinichiro Okamoto $^{1}$. \\ Kanto Study Group for Cell Therapy (KSGCT)
}

Received: 13 April 2020 / Revised: 3 August 2020 / Accepted: 28 August 2020 / Published online: 4 September 2020

(c) Japanese Society of Hematology 2020

\begin{abstract}
Busulfan (Bu) has been used in combination with fludarabine (Flu; BuFlu) or cyclophosphamide (Cy; BuCy) as conditioning for allogeneic hematopoietic stem cell transplantation (HSCT). This multi-institutional prospective study compared pharmacokinetic (PK) parameters of Bu between BuFlu and BuCy. Plasma Bu concentrations were measured by high-performance liquid chromatography at the first dose of the first and fourth days of intravenous $\mathrm{Bu}$ administrations (total of 16 doses of $0.8 \mathrm{mg} / \mathrm{kg}$ ). Thirty-seven patients were evaluable (BuFlu, $N=18 ; \mathrm{BuCy}, N=19)$. The median age was significantly higher in $\mathrm{BuFlu}$. In BuFlu, the median area under the blood concentration-time curve of $\mathrm{Bu}$ on the fourth day was $1183 \mu \mathrm{mol} \mathrm{min} / \mathrm{L}$ (range 808-1509), which was significantly higher than that on the first day [1095 $\mu \mathrm{mol} \mathrm{min/L} \mathrm{(range} \mathrm{822-1453),} P<0.01]$. In contrast, such differences were not observed in BuCy. Consistently, there was a significant decrease in the clearance of $\mathrm{Bu}$ on the fourth day as compared with the first day in BuFlu. These results suggest that the PK of Bu was altered during the co-administration of Flu, which was not the case with Cy. A large-scale study is required to evaluate the significance of the differences in the PK of Bu between the conditionings on HSCT outcomes.
\end{abstract}

Keywords Busulfan $\cdot$ Pharmacokinetics $\cdot$ Allogeneic stem cell transplantation

\section{Introduction}

Busulfan $(\mathrm{Bu})$, an alkylating agent, has been widely used in the conditioning for autologous and allogeneic hematopoietic stem cell transplantation (HSCT), initially in combination with cyclophosphamide (Cy, BuCy) $[1,2]$. BuCy

Taku Kikuchi

taku_k_1123@mac.com

1 Division of Hematology, Department of Medicine, Keio University School of Medicine, 35 Shinanomachi, Shinjuku-ku, Tokyo 160-8582, Japan

2 Department of Hematology, Chiba University Hospital, Chiba, Japan

3 Department of Hematology, International University of Health and Welfare School of Medicine, Chiba, Japan

4 Department of Internal Medicine, Chiba Aoba Municipal Hospital, Chiba, Japan has become one of the most commonly used myeloablative conditioning regimens. When oral formulations of $\mathrm{Bu}$ were used, blood levels of Bu varied greatly among individuals, mainly because of differences in intestinal absorption and first-pass effects [3]. As a result, graft failure and disease recurrence were associated with suboptimal blood 
concentrations of $\mathrm{Bu}$. Conversely, adverse events such as sinusoidal obstruction syndrome (SOS) were reported to be increased in association with high blood concentrations of $\mathrm{Bu}[4,5]$. The intravenous formulation of $\mathrm{Bu}$ has contributed to the stable intraindividual and inter-individual pharmacokinetics $(\mathrm{PK})$ of Bu leading to reduced toxicity and transplant-related mortality and improved survival $[6,7]$.

Fludarabine (Flu) is a purine analogue that suppresses lymphocyte proliferation and induces apoptosis. In the setting of allogeneic HSCT, Flu has been used as a key agent of reduced-intensity conditioning. $\mathrm{Bu}$, in combination with Flu (BuFlu), has become one of the common conditionings in this setting based on its more favorable toxicity profile as compared with Cy $[8,9]$. BuFlu not containing Cy can also be used in the setting of post-transplant Cy for haploidentical transplantation and is expected to be increasingly used [10].

A variety of agents can affect Bu metabolism. Among them, previous studies demonstrated a potential of Flu to interact with $\mathrm{Bu}$, resulting in a significant decrease in the clearance of $\mathrm{Bu}$ and an increase in the area under the blood concentration-time curve (AUC) [11-13]. This was not the case in the setting of BuCy [11-15]. However, the route and the doses of $\mathrm{Bu}$ administration, as well as the timing of PK analysis, varied among those studies. In this prospective study, we performed a PK analysis of Bu in patients receiving 4-day fixed-dose intravenous $\mathrm{Bu}$ as part of BuFlu or BuCy conditioning. We compared the PK parameters between the two regimens to clarify the effect of concomitant Flu on the PK of Bu.

\section{Patients and methods}

\section{Study design}

This multi-institutional study was performed by the Kanto Study Group for Cell Therapy (KSGCT) and evaluated the influences of Flu and $\mathrm{Cy}$ on the $\mathrm{PK}$ of $\mathrm{Bu}$ administered intravenously in recipients of allogeneic HSCT.

This study was approved by the institutional review board of each participating center and was registered in the UMIN Clinical Trial Registry (ID UMIN000018693). All patients provided written informed consent using forms approved by each institution. The primary endpoint of this study is to evaluate the difference in the AUC between the first and fourth days of 4-day Bu administration in BuFlu. Secondary endpoints include the analysis of other PK parameters and a comparison between BuFlu and $\mathrm{BuCy}$. Based on our preliminary evaluation, a $15.2 \%$ increase in the AUC of Bu was predicted after 4-day Bu administration in BuFlu (data not shown). In our study, the optimal AUC for $\mathrm{Bu}$ was $950-1250 \mu \mathrm{mol} \mathrm{min} / \mathrm{L}$ with a target AUC of $1250 \mu \mathrm{mol} \mathrm{min} / \mathrm{L}$ [16]. Based on these data, the increase in the AUC of Bu after 4-day administration with Flu was predicted to be $1250 \times 0.152=190 \mu \mathrm{mol} \mathrm{min} / \mathrm{L}$, and thus $200 \mu \mathrm{mol} \mathrm{min} / \mathrm{L}$ was adopted in our study. Standard deviation was set at 270 according to a previous study [17]. With $\alpha$ set to 0.05 (two sided) and power $1-\beta$ set to 0.8 , the number of samples required was 17 . We estimated a sampling error of $20 \%$, and the number of samples needed was determined to be 20 .

\section{Patients}

Study patients were enrolled from July 2014 to July 2018 at the participating institutions. Primary inclusion criteria were age 16 years or older; a diagnosis of acute myelogenous leukemia, acute lymphoblastic leukemia, chronic myelogenous leukemia, or myelodysplastic syndrome; and administration of 4-day intravenous $\mathrm{Bu}$ in 16 divided doses as part of the conditioning for allogeneic HSCT in combination with Flu or Cy. Exclusion criteria were hepatic dysfunction defined by aspartate aminotransferase or alanine aminotransferase exceeding twice the normal upper limit, the use of itraconazole or metronidazole, the use of anticonvulsants other than valproic acid during the conditioning, and the use of other antineoplastic agents and/or total body irradiation as part of conditioning.

\section{Conditioning regimen}

In $\mathrm{BuCy}$, patients received $\mathrm{Bu}$ from Day 7 to 4 and $\mathrm{Cy}$ on Day 3 and 2. In the BuFlu group, patients received $\mathrm{Bu}$ from Day 7 to 4 and Flu from Day 8 to 3 . Bu was administered at $0.8 \mathrm{mg} / \mathrm{kg}$ body weight intravenously over $2 \mathrm{~h}$ every $6 \mathrm{~h}$ for 4 days ( 16 doses in total). All patients received valproic acid for the prophylaxis of Bu-associated seizure. Flu was administered intravenously at $25-30 \mathrm{mg} / \mathrm{kg}$ body weight for $1 \mathrm{~h}$ once daily. Cy was administered intravenously at $60 \mathrm{mg} / \mathrm{kg}$ body weight for $3 \mathrm{~h}$ once daily. The dose of $\mathrm{Bu}$ was calculated using actual body weight if it was less than ideal body weight (IBW) or adjusted ideal body weight (AIBW) if actual body weight was greater than ideal body weight. AIBW and IBW were calculated according to these equations:

AIBW $(\mathrm{kg})=\mathrm{IBW}(\mathrm{kg})+($ Actual body weight $(\mathrm{kg})-\mathrm{IBW}(\mathrm{kg})) \times 1 / 3, \mathrm{IBW}=22(\text { height }(\text { meter }))^{2}$. 


\section{Sample collection and pharmacokinetic analysis}

Blood samples $(5 \mathrm{~mL})$ for the $\mathrm{PK}$ analysis of $\mathrm{Bu}$ were obtained at the timing of the 1st and 13th Bu infusions. These samples were timed for the first dose before the start of $\mathrm{Bu}$ administration on the first day and the first dose on the last (fourth) day of Bu administration. For the two timings of analysis, blood samples were obtained just before starting an infusion of $\mathrm{Bu}$, and 0, 120, and 240 min after the end of the infusion. Separated plasma samples were immediately cryopreserved until the $\mathrm{Bu}$ concentration measurements. Plasma Bu concentrations were measured by highperformance liquid chromatography basically as previously reported $[18,19]$. The PK parameters of AUC and clearance were calculated from the blood concentration data using the PK analysis software Phoenix ${ }^{\circledR}$ WinNonlin ${ }^{\circledR} 7.0$ (Certara LP, Princeton, NJ, USA).

\section{Statistical analysis}

Comparisons of the patient characteristics and PK parameters between the BuFlu and BuCy groups were performed using Fisher's exact test or the Mann-Whitney $U$ test as appropriate. The PK parameters of $\mathrm{Bu}$ were compared between the 1st and 13th doses in the BuFlu and BuCy groups using the Wilcoxon signed-rank test. $P$ values less than $0.05 \%$ were determined to be statistically significant. Statistical analysis was performed using JMP version 14 (SAS Institute Inc., Cary, NC, USA), and EZR [20].

\section{Results}

\section{Patient characteristics}

In total, 40 patients were enrolled into this study (BuFlu, $N=20 ; \mathrm{BuCy}, N=20)$. One patient in the BuCy group was excluded from the study because of the patient's poor general condition before initiating conditioning. Two cases in the BuFlu group were excluded from the analysis because of blood collection error $(N=1)$ and outliner of AUC of Bu $(N=1)$. The characteristics of the 37 evaluated patients are shown in Table 1. There were differences between BuFlu and $\mathrm{BuCy}$ in age, prothrombin time, estimated glomerular filtration rate (eGFR), and underlying diseases. Body weight and liver enzymes did not differ significantly between the two groups. The BuFlu group had more patients with myelodysplastic syndrome and no patients with chronic myeloid leukemia. No patients received deferasirox at the start of conditioning.

\section{Pharmacokinetics of busulfan}

The PK parameters of $\mathrm{Bu}$ are shown in Table 2. In the BuFlu group, the median AUC of Bu was $1183 \mu \mathrm{mol} \mathrm{min/L}$ (range 808-1509) on the fourth day, which was significantly higher than that on the first day $[1095 \mu \mathrm{mol} \mathrm{min} / \mathrm{L}$ (range 822-1453), $P<0.01$ ]. In contrast, although a similar trend was observed in the BuCy group, it was not statistically different $[1188 \mu \mathrm{mol} \mathrm{min} / \mathrm{L}$ (range $728-1654$ ) vs. $1154 \mu \mathrm{mol} \mathrm{min} / \mathrm{L}$ (range 604-1634), $P=0.08$ ]. In the BuFlu group, the clearance of $\mathrm{Bu}$ of the 4th day was significantly lower on the fourth day than on the first $(P=0.02)$, whereas this was not the case in the BuCy group. In both groups, the
Table 1 Patient characteristics $(N=37)$

\begin{tabular}{lllc}
\hline & BuFlu $(N=18)$ & BuCy $(N=19)$ & $P$ value \\
\hline Male/female & $14 / 4$ & $13 / 6$ & 0.71 \\
Age, years, median (range) & $60(50-66)$ & $47(22-54)$ & $<0.001$ \\
Body weight, median (range) (kg) & $63.8(36.9-85)$ & $56.5(47.4-85.6)$ & 0.81 \\
Adjusted body weight, median (range) $(\mathrm{kg})$ & $61.7(36.9-74.8)$ & $56.5(47.4-76.0)$ & 0.93 \\
eGFR, median (range) (mL/min) & $86.5(52.6-135.3)$ & $119.4(77.5-237.7)$ & $<0.001$ \\
AST, median (range) (IU/L) & $17(8-30)$ & $21(12-37)$ & 0.09 \\
ALT, median (range) (IU/L) & $14(5-39)$ & $22(8-71)$ & 0.15 \\
PT, median (range) (\%) & $97(72-106)$ & $108(73-121)$ & $<0.05$ \\
Total bilirubin, median (range) (mg/dL) & $0.6(0.4-1.4)$ & $0.5(0.2-1.1)$ & 0.10 \\
Underlying disease & & & $<0.05$ \\
Acute myeloid leukemia & 12 & 14 & \\
Myelodysplastic syndrome & 6 & 2 & 3 \\
Chronic myeloid leukemia & 0 & & \\
\hline
\end{tabular}

$B u$ busulfan, $C y$ cyclophosphamide, $F l u$ fludarabine, $e G F R$ estimated glomerular filtration rate, $P T$ prothrombin time, $A S T$ aspartic aminotransferase, $A L T$ alanine aminotransferase 
Table 2 Pharmacokinetc parameters

\begin{tabular}{|c|c|c|c|c|c|c|}
\hline & \multicolumn{3}{|l|}{ BuFlu $(N=18)$} & \multicolumn{3}{|l|}{$\operatorname{BuCy}(N=19)$} \\
\hline & 1st day & 4th day & $P$ & 1st day & 4th day & $P$ \\
\hline AUC, median (range) $(\mu \mathrm{mol} \mathrm{min/L)}$ & $1095(822-1453)$ & $1183(808-1509)$ & $<0.05$ & $1154(604-1634)$ & $1188(728-1654)$ & 0.08 \\
\hline Volume of distribution, median (range) $(\mathrm{L} / \mathrm{kg})$ & $0.70(0.59-1.07)$ & $0.52(0.39-0.66)$ & $<0.01$ & $0.67(0.07-0.97)$ & $0.47(0.06-0.90)$ & $<0.01$ \\
\hline$C_{\text {max }}$, median (range) $(\mathrm{ng} / \mathrm{mL})$ & $866(630-1014)$ & $1112(844-1369)$ & $<0.01$ & $867(644-1289)$ & $1134(705-1605)$ & $<0.01$ \\
\hline Half-life, median (range) (h) & $2.88(2.24-3.79)$ & $3.66(2.65-4.60)$ & $<0.01$ & $2.79(1.84-4.74)$ & $3.28(2.16-7.57)$ & $<0.05$ \\
\hline Clearance, median (range) $(\mathrm{L} / \mathrm{h})$ & $10.88(7.15-16.4)$ & $10.33(6.61-14.0)$ & $<0.05$ & $10.27(7.26-16.1)$ & $9.76(6.93-16.42)$ & 0.23 \\
\hline
\end{tabular}

$B u$ busulfan, $C y$ cyclophosphamide, $F l u$ fludarabine, $A U C$ area under the blood concentration-time curve, $C_{\max }$ maximum calculated plasma concentration

volume of distribution, maximum calculated plasma concentration $\left(C_{\max }\right)$, and half-time differed significantly between the first and fourth days. There were no statistically significant differences in the AUC or clearance of Bu between BuFlu and BuCy at any evaluation timing.

\section{Graft failure, sinusoidal obstructive syndrome, and disease relapse}

One patient experienced primary graft failure in the BuFlu group, but none did so in the BuCy group. One patient developed SOS in the BuFlu group, but none did so in the $\mathrm{BuCy}$ group. One patient in each group underwent allogeneic HSCT with active disease and did not achieve remission after transplantation. In addition, there were six cases of relapse in the BuCy group and two in the Bu/Flu group. The cumulative incidences of disease relapse/progression at 1 year were $11.1 \%$ (95\% CI 1.7-30.4\%) in the BuFlu group and $21.1 \%$ (95\% CI 6.3-41.6\%) in the BuCy group; the difference was not significant $(P=0.13)$.

\section{Discussion}

In this prospective study evaluating the $\mathrm{PK}$ of $\mathrm{Bu}$ used as a part of myeloablative conditioning for allogeneic HSCT, the AUC and clearance of $\mathrm{Bu}$ on the fourth day of $\mathrm{Bu}$ administration was significantly altered as compared with those on the first day in patients receiving BuFlu. In contrast, no such alterations of PK parameters were observed in patients receiving BuCy. Our findings suggest that co-administration of Flu has the potential to affect the PK of $\mathrm{Bu}$ in the later phase of conditioning, increasing the AUC of $\mathrm{Bu}$.

Several reports have evaluated the effect of Flu on the $\mathrm{PK}$ of $\mathrm{Bu}$, but the results were contradictory $[11,13,21]$. In one study, the clearance of Bu was lower at the last dose of $\mathrm{Bu}$ than at the first dose in the 4-day Bu-containing regimen [13]. Another study demonstrated that a significant decrease in the clearance of $\mathrm{Bu}$ was more frequent in patients receiving $\mathrm{Bu}$ concomitantly or consecutively with Flu in those receiving $\mathrm{BuCy}$ [11]. On the other hand, another study showed that Flu did not affect the PK of Bu [21]. Therefore, it is not conclusive that Flu has a significant effect on the PK of Bu. However, the mechanism by which Flu reduces the clearance of $\mathrm{Bu}$ and/or increases the AUC of $\mathrm{Bu}$ is unknown. Since both $\mathrm{Bu}$ and Flu are known to be metabolized by distinct pathways-rapid dephosphorylation in the plasma and phosphorylation by deoxycytidine kinase for Flu and glutathione S-transferases (GST) in the liver for $\mathrm{Bu}$-it is impossible to speculate on the mechanisms underlying the interaction of Flu with $\mathrm{Bu}[15,22]$.

There were limitations to our study. One was the small number of subjects evaluated. Another was the lack of data on glutathione S-transferase (GST) polymorphism in each patient, which was known to be associated with interindividual variation in the PK parameters of $\mathrm{Bu}[23,24]$. There are subtypes of GST as well as genetic polymorphisms in GSTA1, GSTM1, GSTP1, and GSTT1. Kusama et al. showed that 9 of 12 (75\%) Japanese patients had GSTA $1 * A / * A$, which was associated with a significantly higher clearance of $\mathrm{Bu}$ and a lower $\mathrm{Bu}$ concentration compared to GSTA $1 * A / * B$ [23]. Terakura et al. reported similar findings in Japanese patients [25].

Another limitation was the difference in age between the groups. The BuFlu group was significantly older than the BuCy group. Aging is associated with several physiological changes that can affect drug PK and pharmacodynamics [26, 27]. Age-dependent differences in the PK of $\mathrm{Bu}$ have been reported in children having a higher distribution volume and clearance than adults after oral $\mathrm{Bu}$ administration, resulting in reduced toxicity and efficacy [28]. In contrast, other investigators have shown increased $\mathrm{Bu}$ clearance in patients older than 60 years compared with younger patients [29]. Therefore, the effect of age on $\mathrm{Bu}$ metabolism has not been defined. An age-adjusted comparative study is required to determine whether aging affects the $\mathrm{PK}$ of $\mathrm{Bu}$.

In conclusion, our results suggest that the $\mathrm{PK}$ of $\mathrm{Bu}$ was affected in combination with Flu by decreasing the clearance, and this, in turn, increased the AUC, whereas no such 
effect was observed in combination with Cy. A larger scale study is required to evaluate further the effect of Flu on the $\mathrm{PK}$ of $\mathrm{Bu}$ as well as the impact of that effect on transplant outcomes.

Author contribution TK and TM took care of the patients, collected and analyzed data, and wrote the manuscript; $\mathrm{CO}, \mathrm{MO}, \mathrm{HS}, \mathrm{HY}, \mathrm{MO}$, YK, JK, YT, YH, TM, ES, KS, YN, and AY took care of the patients and provided data and important opinions; $\mathrm{KM}$ and $\mathrm{KM}$ performed pharmacokinetic analysis of busulfan; SO provided important opinions and approved the final version of the manuscript.

\section{Compliance with ethical standards}

Conflict of interest TM received research funding from MSD, Novartis Pharma, LSI Medience, Medical \& Biological Laboratories, and Asahi Kasei Corporation; and personal fees from Pfizer Inc., MSD, Janssen Pharma, Sumitomo Dainippon Pharma, Novartis Pharma, Kyowa Kirin, Chugai Pharmaceutical, Shionogi \& Co., Japan Blood Products Organization, Takeda Pharmaceutical, Ono Pharmaceutical, Shire, Eisai, and Astellas Pharma. SO received research funding from Shionogi \& Co., Otsuka Pharmaceutical Co., Ltd., and Sanofi K.K.

\section{References}

1. Santos GW, Tutschka PJ, Brookmeyer R, Saral R, Beschorner WE, Bias WB, et al. Marrow transplantation for acute nonlymphocytic leukemia after treatment with busulfan and cyclophosphamide. N Engl J Med. 1983;309:1347-53.

2. Tutschka PJ, Copelan EA, Klein JP. Bone marrow transplantation for leukemia following a new busulfan and cyclophosphamide regimen. Blood. 1987;70:1382-8.

3. Hassan M, Ljungman P, Bolme P, Ringden O, Syruckova Z, Bekassy A, et al. Busulfan bioavailability. Blood. 1994;84:2144-50.

4. Slattery JT, Clift RA, Buckner CD, Radich J, Storer B, Bensinger WI, et al. Marrow transplantation for chronic myeloid leukemia: the influence of plasma busulfan levels on the outcome of transplantation. Blood. 1997;89:3055-60.

5. Slattery JT, Sanders JE, Buckner CD, Schaffer RL, Lambert $\mathrm{KW}$, Langer FP, et al. Graft-rejection and toxicity following bone marrow transplantation in relation to busulfan pharmacokinetics. Bone Marrow Transplant. 1995;16:31-42.

6. Kim SE, Lee JH, Choi SJ, Lee JH, Ryu SG, Lee KH. Morbidity and non-relapse mortality after allogeneic bone marrow transplantation in adult leukemia patients conditioned with busulfan plus cyclophosphamide: a retrospective comparison of oral versus intravenous busulfan. Haematologica. 2005;90:285-6.

7. Kashyap A, Wingard J, Cagnoni P, Roy J, Tarantolo S, Hu W, et al. Intravenous versus oral busulfan as part of a busulfan/ cyclophosphamide preparative regimen for allogeneic hematopoietic stem cell transplantation: decreased incidence of hepatic venoocclusive disease (HVOD), HVOD-related mortality, and overall 100-day mortality. Biol Blood Marrow Transplant. 2002;8:493-500.

8. Bornhauser M, Storer B, Slattery JT, Appelbaum FR, Deeg HJ, Hansen J, et al. Conditioning with fludarabine and targeted busulfan for transplantation of allogeneic hematopoietic stem cells. Blood. 2003;102:820-6.
9. de Lima M, Couriel D, Thall PF, Wang X, Madden T, Jones R, et al. Once-daily intravenous busulfan and fludarabine: clinical and pharmacokinetic results of a myeloablative, reduced-toxicity conditioning regimen for allogeneic stem cell transplantation in AML and MDS. Blood. 2004;104:857-64.

10. Kanakry CG, O’Donnell PV, Furlong T, de Lima MJ, Wei W, Medeot M, et al. Multi-institutional study of post-transplantation cyclophosphamide as single-agent graft-versus-host disease prophylaxis after allogeneic bone marrow transplantation using myeloablative busulfan and fludarabine conditioning. J Clin Oncol. 2014;32:3497-505.

11. Yeh RF, Pawlikowski MA, Blough DK, McDonald GB, O'Donnell PV, Rezvani A, et al. Accurate targeting of daily intravenous busulfan with 8-hour blood sampling in hospitalized adult hematopoietic cell transplant recipients. Biol Blood Marrow Transplant. 2012;18:265-72.

12. de Castro FA, Lanchote VL, Voltarelli JC, Colturato VA, Simoes BP. Influence of fludarabine on the pharmacokinetics of oral busulfan during pretransplant conditioning for hematopoietic stem cell transplantation. J Clin Pharmacol. 2013;53:1205-11.

13. Perkins JB, Kim J, Anasetti C, Fernandez HF, Perez LE, Ayala $\mathrm{E}$, et al. Maximally tolerated busulfan systemic exposure in combination with fludarabine as conditioning before allogeneic hematopoietic cell transplantation. Biol Blood Marrow Transplant. 2012;18:1099-107.

14. Rezvani AR, McCune JS, Storer BE, Batchelder A, Kida A, Deeg HJ, et al. Cyclophosphamide followed by intravenous targeted busulfan for allogeneic hematopoietic cell transplantation: pharmacokinetics and clinical outcomes. Biol Blood Marrow Transplant. 2013;19:1033-9.

15. Bonin $M$, Pursche $S$, Bergeman T, Leopold T, Illmer T, Ehninger G, et al. F-ara-A pharmacokinetics during reducedintensity conditioning therapy with fludarabine and busulfan. Bone Marrow Transplant. 2007;39:201-6.

16. Andersson BS, Thall PF, Madden T, Couriel D, Wang X, Tran HT, et al. Busulfan systemic exposure relative to regimenrelated toxicity and acute graft-versus-host disease: defining a therapeutic window for i.v. BuCy2 in chronic myelogenous leukemia. Biol Blood Marrow Transplant. 2002;8:477-85.

17. Ryu SG, Lee JH, Choi SJ, Lee JH, Lee YS, Seol M, et al. Randomized comparison of four-times-daily versus oncedaily intravenous busulfan in conditioning therapy for hematopoietic cell transplantation. Biol Blood Marrow Transplant. 2007; 13:1095-105.

18. Chow DS, Bhagwatwar HP, Phadungpojna S, Andersson BS. Stability-indicating high-performance liquid chromatographic assay of busulfan in aqueous and plasma samples. J Chromatogr B Biomed Sci Appl. 1997;704:277-88.

19. Matsumoto K, Uchida N, Sakurai A, Taniguchi S, Morita K. Clinical application of the dried blood spot method in the measurement of blood busulfan concentration. Biol Blood Marrow Transplant. 2016;22:1968-73.

20. Kanda Y. Investigation of the freely available easy-to-use software 'EZR' for medical statistics. Bone Marrow Transplant. 2013;48:452-8.

21. Almog S, Kurnik D, Shimoni A, Loebstein R, Hassoun E, Gopher A, et al. Linearity and stability of intravenous busulfan pharmacokinetics and the role of glutathione in busulfan elimination. Biol Blood Marrow Transplant. 2011;17:117-23.

22. Gandhi V, Plunkett W. Cellular and clinical pharmacology of fludarabine. Clin Pharmacokinet. 2002;41:93-103.

23. Kusama M, Kubota T, Matsukura Y, Matsuno K, Ogawa S, Kanda Y, et al. Influence of glutathione $S$-transferase A 1 polymorphism on the pharmacokinetics of busulfan. Clin Chim Acta. 2006;368:93-8. 
24. Kim SD, Lee JH, Hur EH, Lee JH, Kim DY, Lim SN, et al. Influence of GST gene polymorphisms on the clearance of intravenous busulfan in adult patients undergoing hematopoietic cell transplantation. Biol Blood Marrow Transplant. 2011;17:1222-30.

25. Terakura S, Onizuka M, Fukumoto M, Kuwatsuka Y, Kohno A, Ozawa Y, et al. Analysis of glutathione $S$-transferase and cytochrome $\mathrm{P} 450$ gene polymorphism in recipients of doseadjusted busulfan-cyclophosphamide conditioning. Int J Hematol. 2020;111:84-92.

26. Egorin MJ. Cancer pharmacology in the elderly. Semin Oncol. 1993;20:43-9.

27. Tumer N, Scarpace PJ, Lowenthal DT. Geriatric pharmacology: basic and clinical considerations. Annu Rev Pharmacol Toxicol. 1992;32:271-302.
28. Grochow LB, Krivit W, Whitley CB, Blazar B. Busulfan disposition in children. Blood. 1990;75:1723-7.

29. Beumer JH, Owzar K, Lewis LD, Jiang C, Holleran JL, Christner SM, et al. Effect of age on the pharmacokinetics of busulfan in patients undergoing hematopoietic cell transplantation; an alliance study (CALGB 10503, 19808, and 100103). Cancer Chemother Pharmacol. 2014;74:927-38.

Publisher's Note Springer Nature remains neutral with regard to jurisdictional claims in published maps and institutional affiliations. 